\title{
Role of Self-Regulation and Self-Care With Academic Performance
}

\author{
Mary Ann Hollingsworth \\ University of West Alabama, Livingston, AL, USA
}

\begin{abstract}
Life demands compete with academic study for all levels of education. Higher education now includes strong representation of multiple generations as well as strong representation of both campus-based and online students. Research indicates that students at various stages and in different formats of academic study present some different needs as well as different strategies for managing these needs concurrently with academic study. Research has supported the use of self-care behaviors in reduction of stress, with some studies indicating also an association of self-care and academic performance. In addition, research has also indicated role of student-driven factors such as self-regulation in academic performance. Much of self-care behaviors such as physical activity, consumption of fruits and vegetables, and sleep habits include self-regulation. This study examined association of self-care behaviors in physical activity, consumption of fruits and vegetables, and sleep from selected items of the Personal Wellness Questionnaire and Plan and self-regulation from selected scales of the Motivated Strategies for Learning Questionnaire (MSLQ) of Organization, Resource Management, Effort regulation, and Help-Seeking. Results will assist educators in promotion of student self-care and self-regulation behaviors that can facilitate successful academic endeavor. Answers will also provide guidance to educators and institutions on priority of effort in students support for self-care and self-regulation.
\end{abstract}

Keywords: academic self-regulation, student self-care, student wellness, student success

Academic study can produce the challenge and stress for life that is much like the challenge and stress produced with work demands in a person's life. Students in elementary through graduate school are often told that school is a form of work for them, much as the paid work of a "job". Whether a person is working in academic study or on a job, life still demands care of the self in physical, mental, and social well-being. There has been research support for mutual benefit from self-regulation in self-care for health factors with concurrent self-regulation of academic study.

\section{Review of Literature}

Beccaria, Rogers, Burton, and Beccaria (2016) noted the common experience of university students with stress and strain during their academic study. Beccaria, et al., also noted the benefits of coping strategies of self-care to help juggle management of these demands. Their study focused specifically on strategies of health-promoting behaviors. These authors examined both distance and on-campus university students and found no significant difference between needs for self-care nor efficacy of health-promoting behaviors as

Mary Ann Hollingsworth, Ph.D., Assistant Professor, Instructional Leadership and Support, University of West Alabama, Livingston, AL, USA. 
positive coping strategies with stressful impact of academic study. These authors noted that literature provides mixed results on academic performance between campus-based and online students. They also indicated mixture of both internal and external influences on capacity to cope with life distractors to study. These authors found no evidence of influence on health-care-promoting behaviors and grade point average (GPA). Wald (2011) examined the association of three health-promoting behaviors of physical activity, fruit and vegetable intake, and sleep to academic performance. She found that these three behaviors provided significant but weak positive association with grade point average.

Hollingsworth (2010) examined the relationship between dimensions of wellness and academic performance of elementary students through comparison of scores on the Five Factor Wellness Inventory for Elementary Children and current annual state testing of academic content mastery. The results of this study indicated significant correlation between test score in Reading, Language, and Math with social, physical, and coping composites of wellness.

Griggs and Crawford (2017) conducted examination of multiple health-related factors and academic performance of college freshman. These factors included factors of health-hindering behavior such as sexual risk-taking, alcohol use, or drug use as well as factors of health promotion such as hope and emotional well-being. Core Self-Evaluation (CSE) was also examined with a core component of this as locus of control. Their findings indicated that both hope and CSE had important impact on academic performance.

Vermunt (2005) discussed several student factors that impact on the way that students learn and study, three of which relate to student-self-regulation-motivation, work habits, and study skills. Motivation was further described to include meaning-directed, reproduction-directed, or application-directed learning, with meaning-directed learning the only approach with a positive correlation. Vermunt used an Inventory of Learning Styles that included both self-regulation and external regulation learning processes. Self-regulation activities included "planning learning activities, monitoring progress, diagnosing problems, testing one's results, adjusting and reflecting" (p. 213). External regulation learning activities included students yielding to external sources such as "introductions, learning objectives, directions, questions, or assignments from a teacher or textbook author" (p. 213). This inventory also examined a scale on Lack of Regulation, which examined how the student monitored difficulties with regulation of individual learning process. Results of the study indicated some positive relationship between self-regulations strategies and academic and exam performance, but predominately negative associations with external regulations.

Jacobson and Harris (2008) specifically investigated self-regulation of learning with nontraditional students and also the framework of distance learning. They described the tendency of research to indicate student dependence on external motivation and lack of systemic approach to studying. In their study, Jacobson and Harris used the Motivated Strategies for Learning Questionnaire (MSLQ) which included scales relevant to self-regulation - organization, self-regulation, time, study environment, and help-seeking. They provided a definition of self-regulated learning as "a dimensional construct that contained the three aspects of cognition, individual motivation, and goal-directed behavior" (p. 414). Self-regulated learner behavior included planning, organizing, self-instruction, self-monitoring, and self -evaluation at various points within the learning process.

Jacobson and Harris (2008) also noted sequences of processes in self-regulation that included "self-evaluation, seeking information, goal setting and planning, record keeping and self-monitoring, environmental structuring, self-consequences, persistence, rehearsing, and memorization" (p. 414). Examples 
were given such as self-monitoring, setting goals, and adapting learning strategies. A key point was that the student be an active and engaged participant in the learning process.

There seem to be differences in self-regulated learning between non-traditional and traditional students. Jacobson and Harris (2008) indicated that non-traditional students tend to learn strategy from life experiences. The study done by Jacobson and Harris showed results of non-traditional students scoring higher in areas of Organization, Critical Thinking, Metacognitive Self-regulation, and Effort Regulation.

Edelbring and Wahlstrom (2016) indicated that self-regulated learning centers around the three factors of motivation, autonomy, and the student's control of his or her own learning process. They also emphasized the importance of the ability of a student to self-regulate in today's demand for a student to be able to learn anywhere at any time as online learning and mobile application study increase.

Hailikari and Parpala (2014) noted that higher education has for a long time had concerns about study progress of students - the time that it takes for degree completion. They noted that personal situations such as health or financial issues could slow study time. They also noted that institutional factors could bear influence such as student guidance or course availability and sequence. A key finding was that organized study had strong positive correlation with factors such as self-initiative, diligence, and enthusiasm about study.

\section{Health-Promotion Strategies of Promise}

Beccaria, et al. (2016) found that health-promoting behaviors did act as a buffer between student stress and strain with both campus-based and online student participants. They also found that a pathway of health-promoting behaviors was equally predictive of outcomes with campus-based and online students. Suggested strategies to offer by institutions were both pro-active and early intervention strategies that could be offered to either campus-based or online students. One example was a web-based promotion of student well-being that could easily be embedded into course curriculums. Another example was to focus messages on coping, health, and wellbeing of the student versus messages on possible university-desired outcomes such as improved GPAs or student retention.

Often, educators at all levels, speak belief that academic performance is enhanced through effective levels of personal wellness across a person's physical, mental, and even social health. The relationship between dimensions of wellness and academic performance of elementary students through comparison of scores on the Five Factor Wellness Inventory for Elementary Children and current annual state testing of academic content mastery was examined by Hollingsworth (2010). The results of this study indicated significant correlation between test score in Reading, Language, and Math with social, physical, and coping composites of wellness.

The specific items of assessment of wellness in the study indicated that social wellness involved friendship and love such as experienced with family and peers. Physical wellness included exercise and nutrition. Wellness in coping focused on how well a person challenges and stress in everyday life and had capacity to move beyond these.

Griggs and Crawford (2017) conducted examination of multiple health-related factors and academic performance of college freshman. These factors included factors of health-hindering behavior such as sexual risk-taking, alcohol use, or drug use as well as factors of health promotion such as hope and emotional well-being. CSE was also examined with a core component of this as locus of control. Their findings indicated that both hope and CSE had important impact on academic performance. 


\section{Demands of Academic Study}

Beccaria, et al. (2016) noted that literature provides mixed results on academic performance between campus-based and online students. They also indicated mixture of both internal and external influences on capacity to cope with life distractors to study. Mishra (2018) studied the various stressors experienced by students training to be teachers. Those founds in this study seem to be common among undergraduate students. Examples are concern over course grades, monetary concerns, concerns over getting a job when they graduate, and then anxiety after graduation on perhaps delay in getting that job. Mishra also noted that student backgrounds prior to college could influence level of stress, such as a greater adjustment needed with students from a rural background.

Cestari, Riberiro, Florencio, Mendes de Paula Pessoa, Magalhaes, and Barbosa (2017) noted the co-occurring physical distress that can be present with academic stress. In the experience of academic stress as with other life stressors, the physical symptoms can suggest depression or digestive system imbalance. This study found that women especially could also experience increased production of the hormones, cortisol, and adrenaline which could promote emotional exhaustion, anxiety, depression, or even panic.

\section{Self-Regulation}

The health care professions such as medical doctor and nursing are tasked with leading the general populace in self-care of health. Some research has examined the degree to which these professionals regulate their self-care in the academic preparation for their professional practice. Potgieter (2015) noted that these professionals could support and encourage self-care by members of their public they served to the degree that they effectively cared for self. Potgieter found that these professionals in preparation experienced the same challenges in self-care within adjustment to academic study as other students do. Study results indicated need for integration into the core curriculum study on self-care such as the role of physical activity, healthy diets, stress management, time management, and even financial management. This study also indicated the benefits of wellness promotion programs by institutions for students, faculty, and staff.

Self-regulation is innately related to the locus of control with an individual. Marr and Wilcox (2015) described Health Locus of Control as "how much individuals believe they are in control of their current and future health" (p. 122). Internal locus of control is represented with individuals who believe that they have the control over their health outcomes, while external locus of control is represented with individuals who believe that their health outcomes are beyond their personal control and due to factors outside their management. Marr and Wilcox noted that high internal locus of control was predictive of better health outcomes such as less practice of negative health habits and greater practice of positive health habits such as healthier dietary habits.

\section{Conceptual Framework}

Several conceptual frameworks are integrated with this study. Beccaria, et al. (2016) used a framework from occupations stress by Osipow and Spokane (1984) in which there was integration of the three domains of stress, strain, and coping. Stress and strain were mediated by coping. As Beccaria, et al., noted, academic study is work for the student in much the same way that a job with an employer is work.

Self-care models included a framework of health-promoting behavior by Beccaria, et al. (2016) and Marr and Wilcox (2015). Beccaria, et al., examined the health-promoting behaviors of "nutrition, physical activity, stress management, spiritual growth, interpersonal relationships, and health responsibility" (p. 27). These authors 
measured frequency of engagement in these behaviors and found that habit formation of health promoting behaviors countered negative impact of academic stress for campus-based and online students. Beccarria, et al., noted the benefit of institutional promotion of health promoting behaviors through pro-activity in providing encouragement and means for these. Marr and Wilcox (2015) recommended inclusion of assessment of health locus of control with students and then integration of promotional venues with self-efficacy and increased social support to encourage students who might have greater external locus of control.

Both of these models had common messages for institutions and faculty in promotion of student self-care to enhance academic efficacy as well as more optimal whole student wellness. Both models found that health self-care provided positive support for academic efficacy. Both models noted the need for and benefit of institutional promotion of and support of student engagement in health self-care. Finally, both models noted a need for the institutional message of self-care as a core of the academic experience-a message that is consistently communicated in multiple venues of university life.

\section{Purpose of the Study}

This study examined association of self-care behaviors in physical activity, consumption of fruits and vegetables, and sleep from selected items of the Personal Wellness Questionnaire and Plan (Hollingsworth, 2015) and self-regulation from selected scales of the MSLQ (Taylor, 2012) of Organization, Resource Management, Effort regulation, and Help-Seeking. The following hypotheses were presented.

$\mathrm{H}_{\mathrm{a}}$ : There is a positive correlation between student engagement in the self-care behaviors of physical activity, consumption of fruits and vegetables, and sleep and Grade Point Average (GPA).

$\mathrm{H}_{\mathrm{b}}$ : There is a positive correlation between student self-regulation in Organization, Resource Management, Effort regulation, and Help-Seeking and Grade Point Average (GPA).

$\mathrm{H}_{\mathrm{c}}$ : There is a positive correlation between student engagement in the self-care behaviors of physical activity, consumption of fruits and vegetables, and sleep and student self-regulation in Organization, Resource Management, Effort regulation, and Help-Seeking.

\section{Method of Study}

A survey was administered to 301 students in both campus and online courses at UWA, undergraduate and graduate to examine association of self-care behaviors in physical activity, consumption of fruits and vegetables, and sleep from selected items of the Personal Wellness Questionnaire and Plan (Hollingsworth, 2015) and self-regulation from selected scales of the MSLQ (Taylor, 2012) of Organization, Resource Management, Effort regulation, and Help-Seeking. Twenty-one percent of respondents were undergraduate and 79 percent of respondents were graduate students. Twelve percent of respondents were in campus based programs and 88 percent were in a totally online program. The survey included self-report questions for both letter grade and Grade Point Average (GPA) to support confidentiality of participants. This survey was administered through Qualtrics and was anonymous with participants providing no personal identification. A word copy of the survey is attached as Appendix A.

\section{Results of Study}

Study results were analyzed using Qualtrics and trends identified for high and low adherence to national recommendations on the three modalities of self-care as evidenced through physical exercise, consumption of 
fruits and vegetables, and sleep time. Trends were also identified in the 12 factors of academic self-regulation. Respondents self-reported letter grade averages of 95 percent as either an A or a B and self-reported GPAs. Respondents self-reported letter grade averages of 95 percent as either an A or a B and 91 percent as GPA above 3.0, the numerical assignment for a letter grade of a B. The discrepancy in percentages between letter grade and GPA is probably explained by use of self-report versus mining of actual transcript data. Table 1 summarizes factors in self-care activity.

Table 1

Summary of Factors on Self-Care Activity

\begin{tabular}{lll}
\hline Factor & Highest Adherence & Lowest Adherence \\
\hline I do physical exercise at least 20 to 30 minutes a day & At least 2 days a week- $-48 \%$ & Hardly ever-21\% \\
I eat fruits and vegetables, fresh or cooked other than fried & At least 5 servings a day- $-7 \%$ & Hardly every other than fries $-4 \%$ \\
My daily average hours of sleep now is & $7-8$ hours a night $-45 \%$ & 4 or less hours a night $-4 \%$ \\
\hline
\end{tabular}

Results revealed that the population sampled engaged in the self-care habit of physical exercise per the recommended days per wee from the Center for Disease Control (2018) and sleeping the recommended number of sleep hours for adults from the most recent published information from the National Sleep Foundation (2015) at above 45 percent affirmative response. Only seven percent of respondents indicated daily consumption of fruits and vegetables as recommended by the U.S. Food and Drug Administration (2018).

Table 2

Summary of Factors on Academic Self-Regulation

\begin{tabular}{lll}
\hline Factor & Strongly Agree & $\begin{array}{c}\text { Strongly } \\
\text { Disagree }\end{array}$ \\
\hline Organization & & \\
\hline When I study for my courses, I outline the material to help me organize my thoughts. & $33 \%$ & $4 \%$ \\
When I study for a course, I go through readings and class notes to find the most & $59 \%$ & $<1 \%$ \\
important ideas. & $14 \%$ & $18 \%$ \\
\hline I make simple charts, diagrams, or tables to help me organize course material. & & $<1 \%$ \\
\hline Resource Management & $60 \%$ & $1 \%$ \\
\hline I usually study in a place where I can concentrate on my course work. & $39 \%$ & $10 \%$ \\
I make good use of my study time for courses. & $17 \%$ & $6 \%$ \\
I find it easy to stick to a study schedule. & $38 \%$ & $0 \%$ \\
I have a regular place set aside for studying. & $76 \%$ & $3 \%$ \\
I make sure I keep up with weekly assignments for courses. & $34 \%$ & \\
I schedule my life activities to give me sufficient time to study. & $79 \%$ & $0 \%$ \\
\hline Effort Regulation & & $<1 \%$ \\
\hline I work hard to do well in courses even if I don't like what we are doing. & $<1 \%$ \\
Even when course materials are dull and uninteresting, I manage to keep working until I finish. & $72 \%$ & $3 \%$ \\
Even if I feel lazy or bored when studying for classes, I stick with it until I finish what I $61 \%$ & \\
planned to do. &
\end{tabular}

Responses indicated the strongest (over half affirmative responses) self-regulatory habits to be exploration of reading and class notes to discern most important ideas; studying in locations to facilitate concentration; keeping up with weekly assignments; working hard in a course even if student does not like the content, finds content dull and uninteresting, or feels lazy or bored when studying for classes. Effort regulation was most strongly reported of the three areas of academic self-regulation. 
Cross-tabulations were also run on data collected as shown in Table 3. Interestingly, participants indicated the greatest adherence to national recommendations for physical exercise, but when cross-tabulation was run, this did not show strong alignment with academic self-regulation factors. Participants showed the lowest overall adherence to national recommendations for consumption of fruits and vegetables, yet cross-tabulations showed the strongest alignment of this with academic self-regulation factors.

Table 3

Cross-Tabulations of Data

\begin{tabular}{|c|c|c|c|}
\hline Self-Regulation Factor & $\begin{array}{l}\text { Physical Exercise } \\
\text { at least } 4 \text { times a } \\
\text { week }\end{array}$ & $\begin{array}{l}\text { Daily } \\
\text { Consumption } \\
\text { of Fruits and } \\
\text { Vegetables } \\
\end{array}$ & $\begin{array}{l}\text { Sleep at least } 7 \\
\text { hours daily }\end{array}$ \\
\hline $\begin{array}{l}\text { When I study for my courses, I outline the material to help me } \\
\text { organize my thoughts. }\end{array}$ & $6 \%$ & $22 \%$ & $17 \%$ \\
\hline $\begin{array}{l}\text { When I study for a course, I go through readings and class notes to } \\
\text { find the most important ideas. }\end{array}$ & $14 \%$ & $40 \%$ & $29 \%$ \\
\hline $\begin{array}{l}\text { I make simple charts, diagrams, or tables to help me organize course } \\
\text { material. }\end{array}$ & $4 \%$ & $10 \%$ & $7 \%$ \\
\hline I usually study in a place where I can concentrate on my course work. & $12 \%$ & $36 \%$ & $30 \%$ \\
\hline I make good use of my study time for courses. & $9 \%$ & $26 \%$ & $22 \%$ \\
\hline I find it easy to stick to a study schedule. & $5 \%$ & $13 \%$ & $12 \%$ \\
\hline I have a regular place set aside for studying. & $9 \%$ & $23 \%$ & $18 \%$ \\
\hline I make sure I keep up with weekly assignments for courses. & $17 \%$ & $49 \%$ & $38 \%$ \\
\hline I schedule my life activities to give me sufficient time to study. & $7 \%$ & $21 \%$ & $17 \%$ \\
\hline I work hard to do well in courses even if I don't like what we are doing. & $16 \%$ & $49 \%$ & $35 \%$ \\
\hline $\begin{array}{l}\text { Even when course materials are dull and uninteresting, I manage to } \\
\text { keep working until I finish. }\end{array}$ & $17 \%$ & $46 \%$ & $32 \%$ \\
\hline $\begin{array}{l}\text { Even if I feel lazy or bored when studying for classes, I stick with it } \\
\text { until I finish what I planned to do. }\end{array}$ & $13 \%$ & $39 \%$ & $29 \%$ \\
\hline
\end{tabular}

\section{Conclusion}

A strong majority of respondents reported letter grade averages and GPAs over 90 percent. The majority of respondents were engaged in graduate study and online study, both of which require more employment of internal locus of control for both self-care and academic study. In re-examination of the hypotheses, the study revealed the followings.

$\mathrm{H} 1_{\mathrm{a}}$ : There is a positive correlation between student engagement in the self-care behaviors of physical activity, consumption of fruits and vegetables, and sleep and Grade Point Average (GPA). Engagement in national recommendations for physical activity and hours of sleep was reported by over 40 percent of participants. Less than 10 percent of participants reported adherence to the national recommendation for consumption of fruits and vegetables. This could be supported by several life factors such as ease of access to foods other than fruits and vegetables, lack of ease of eating fruits and vegetables "on the go", or expense of eating healthier.

$\mathrm{H}_{\mathrm{b}}$ : There is a positive correlation between student self-regulation in Organization, Resource Management, Effort regulation, and Help-Seeking and Grade Point Average (GPA). Effort regulation was reported as the strongest component with participants. All three areas had responses in most items of over 30 percent. Two items showed less than 20 percent—-student creation of charts, diagrams, or tables to organize study and ease of adherence to a planned study schedule. The results indicate that participants in this study engage in strong academic self-regulation and this is paired with grades in the A and B grade ranges. 
$\mathrm{H} 1_{\mathrm{c}}$ : There is a positive correlation between student engagement in the self-care behaviors of physical activity, consumption of fruits and vegetables, and sleep and student self-regulation in Organization, Resource Management, Effort regulation, and Help-Seeking. Cross-tabulation of results showed the greatest alignment between self-care management and academic self-regulation to be in the consumption of national recommendations of fruits and vegetables. Much weaker alignment was shown between level of physical activity or sleep and academic self-regulation. This suggests the greater effort needed to consume the recommended daily dosage of fruits and vegetables which may be aligned with greater exertion of effort in academic self regulation.

This study was conducted with students at one university and results do not offer the generalizability that could be discerned from further study with other institutions and geographic locations. More detailed assessment of a greater number of factors in both self-care and academic self-regulation would provide additional information on correlation of these two areas. This study examined general trends versus intra-participant results. Conduct of intra-participant study in these areas could be used to guide students with improvement of efficacy in both self-care and academic self-regulation.

\section{References}

Beccaria, 1., Rogers, C., Burton, L., \& Beccaria, G. (2016). Role of health-promoting behaviors for on-campus and distance education students. Distance Education, 37(1), 22-40.

Center for Disease Control. (2018). Physical activity. Retrieved from https://www.cdc.gov/physicalactivity/basics/adults/index.htm

Cestari, E., Riberiro, V., Florencio, R. S., Mendes de Paula Pessoa, V. L., Magalhaes, M, T., \& Barbosa, I. V. (2017). Stress in nursing students: Study on sociodemographic and academic vulnerabilities. Acta Paulista de Enfermagem (Paulista Minutes Nursing), 30(2), 190-196.

Edelbring, S., \& Wahlstron, R. (2016). Dynamics of study strategies and teacher regulation in virtual patient learning activities: A cross sectional survey. BMC Medical Education, 16(122), 1-8.

Food and Drug Administration. (2018). Dietary guidelines. Retrieved from https://health.gov/dietaryguidelines/dga2000/document/build.htm

Griggs, S., \& Crawford, S. L. (2017). Hope, core self-evaluations, emotional well-being, health-risk behaviors, and academic performance in university freshmen. Journal of Psychosocial Nursing, 55(9), 33-42.

Hailikari, T. K., \& Parpala, A. (2014). What impedes or enhances my studying? The interrelation between approaches to learning, factors influencing study progress and earned credits. Teaching in Higher Education, 19(7), 812-824.

Hollingsworth, M. A. (2010). Relationship of friends, physical education, and state test scores: Implications for school counselors. Journal of School Counseling, 8(35), 1-32.

Hollingsworth, M. A. (2015). Wellness: Paradigm for training and practice. In Ideas and research you can use: Vistas 2012. Retrieved from http://www.counseling.org/knowledge-center/vistas

Jacobson, R. R., \& Harris, S. M. (2008). Does the type of campus influence self-regulated learning as measured by the motivated strategies for learning questionnaire (MSLQ)? Education, 128(3), 412-431.

Marr, J., \& Wilcox, S. (2015). Self efficacy and social support mediate the relationship between internal health locus of control and health behaviors in college students. Journal of Health Education, 46(3), 122-131.

Mishra, M. (2018). A comparative study on academic stress level of male and female B.Ed. students. Indian Journal of Health \& Wellbeing, 9(1), 131-135.

National Sleep Foundation. (2015). National Sleep Foundation recommends new sleep times. Retrieved from https://sleepfoundation.org/press-release/national-sleep-foundation-recommends-new-sleep-times

Osipow, S. H. \& Spokane, A. R. (1984). Measuring occupational stress, strain, and coping. Applied Social Psychology Annual, 5 , 67-86.

Potgieter, S. (2015). Wellness as a virtue in Health Sciences students: Are they practising what they preach? South African Journal of Clinical Nutrition, 28(4), 152-153. 
Taylor, R. T. (2012). Revie or the Motivated Strategies for Learning Questionnaire (MLSQ) using reliability generalization techniques to assess scale reliability (Doctoral dissertation). Retrieved from ERIC (ED546666). Auburn University, Auburn, AL.

Vermunt, J. D. (2005). Relations between student learning patterns and personal and contextual factors and academic performance. Higher Education, 49, 205-234.

Wald, A. (2011). Relationship of key health-promoting behaviors with self-rated health and academic performance in college students. Dissertations Abstracts International, 71(10-A), 3547.

\section{Appendix A: Survey}

These are questions about some of your habits while a student. Please first answer the general demographic questions and then answer each question with the response that best fits you.

\section{Demographic Questions}
A. Classification
1. Freshman
2. Sophomore
3. Junior
4. Senior
5. Graduate Student-Masters
6. Graduate Student—Educational Specialist
B. Type of program
1. Campus
2. Online
C. Age range
1.25 or younger
2. $26-35$
3. 36-45
4. 46 or older
D. Type in what culture or ethnicity you identify with
E. Type in what gender you identify with

\section{Survey Questions}

1. I do physical exercise at least 20 to 30 minutes a day.
a. 7 days a week
b. 4-5 days a week
c. 2-3 days a week
d. At least once a week
e. A few times a month
f. Hardly ever

2. I eat fruits and vegetables, fresh or cooked other than fried.
a. At least five servings a day
b. One or two servings a day
c. A few times a week 
d. Hardly every other than fries

3. My daily average hours of sleep now is
a. 7-8 hours a night
b. 5-6 hours a night
c. 4 or less hours a night

4. When I study for my courses, I outline the material to help me organize my thoughts.
a. Strongly agree
b. Somewhat agree
c. Neither agree nor disagree
d. Somewhat disagree
e. Strongly disagree

5. When I study for a course, I go through readings and class notes to find the most important ideas.
a. Strongly agree
b. Somewhat agree
c. Neither agree nor disagree
d. Somewhat disagree
e. Strongly disagree

6. I make simple charts, diagrams, or tables to help me organize course material.
a. Strongly agree
b. Somewhat agree
c. Neither agree nor disagree
d. Somewhat disagree
e. Strongly disagree

7. I usually study in a place where I can concentrate on my course work.
a. Strongly agree
b. Somewhat agree
c. Neither agree nor disagree
d. Somewhat disagree
e. Strongly disagree

8. I make good use of my study time for courses.
a. Strongly agree
b. Somewhat agree
c. Neither agree nor disagree
d. Somewhat disagree
e. Strongly disagree

9. I find it easy to stick to a study schedule.
a. Strongly agree
b. Somewhat agree
c. Neither agree nor disagree
d. Somewhat disagree
e. Strongly disagree 
10. I have a regular place set aside for studying.
a. Strongly agree
b. Somewhat agree
c. Neither agree nor disagree
d. Somewhat disagree
e. Strongly disagree

11. I make sure I keep up with weekly assignments for courses.
a. Strongly agree
b. Somewhat agree
c. Neither agree nor disagree
d. Somewhat disagree
e. Strongly disagree

12. I schedule my life activities to give me sufficient time to study.
a. Strongly agree
b. Somewhat agree
c. Neither agree nor disagree
d. Somewhat disagree
e. Strongly disagree

13. I work hard to do well in courses even if I don't like what we are doing.
a. Strongly agree
b. Somewhat agree
c. Neither agree nor disagree
d. Somewhat disagree
e. Strongly disagree

14. Even when course materials are dull and uninteresting, I manage to keep working until I finish.
a. Strongly agree
b. Somewhat agree
c. Neither agree nor disagree
d. Somewhat disagree
e. Strongly disagree

15. Even if I feel lazy or bored when studying for classes, I stick with it until I finish what I planned to do.
a. Strongly agree
b. Somewhat agree
c. Neither agree nor disagree
d. Somewhat disagree
e. Strongly disagree

16. What is your letter grade average in your courses at this time?
a. I have an A average
b. I have a B average
c. I have a $\mathrm{C}$ average
d. I have a D average 
e. I have an F average

17. What is your numerical Grade Point Average (GPA) in your courses at this time?
a. 4.00
b. $3.00-3.99$
c. $2.00-2.99$
d. $1.00-1.99$
e. Less than 1.00 